Orthopaedics

\section{Calcifying cystic lesion of calcaneum}

\section{H Sharma, G R Taylor}

Answers on $p 244$.

A 28 year old woman of Asian origin presented with a seven year history of intermittent right heel pain. She had no history of trauma. She had suffered from intestinal tuberculosis in childhood, which was confirmed after a histological examination of the appendix. There were no other musculoskeletal sites involved. Systemic

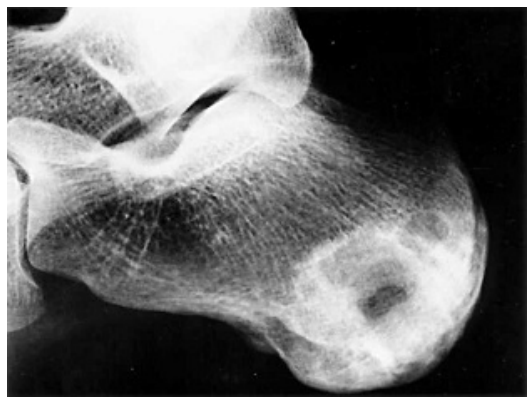

Figure 1 Lateral view of calcaneum.

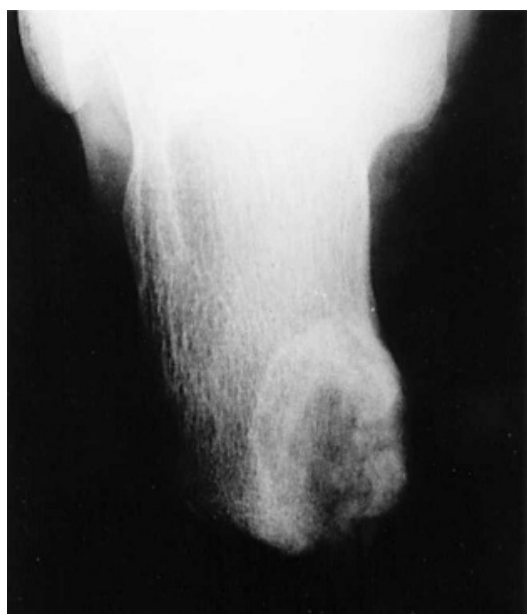

Figure 2 Axial view of calcaneum. examination was unremarkable, but examination of the foot and ankle disclosed a significant medial calcaneal tenderness without limitation of ankle and subtalar motion. Haematological and biochemical markers were within normal limits. Lateral (fig 1) and axial

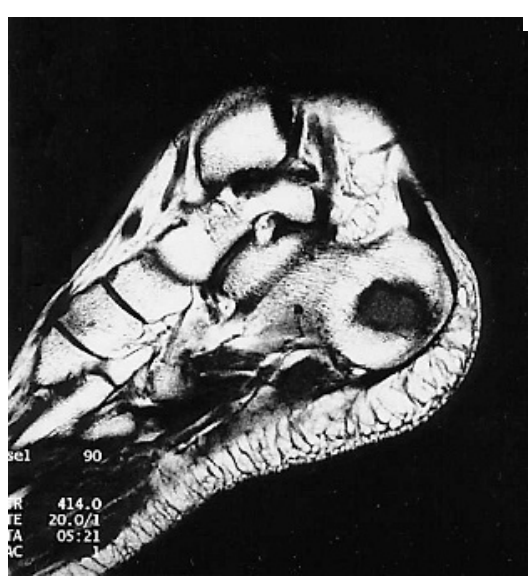

Figure 3 MRI scan: TIW sagittal.

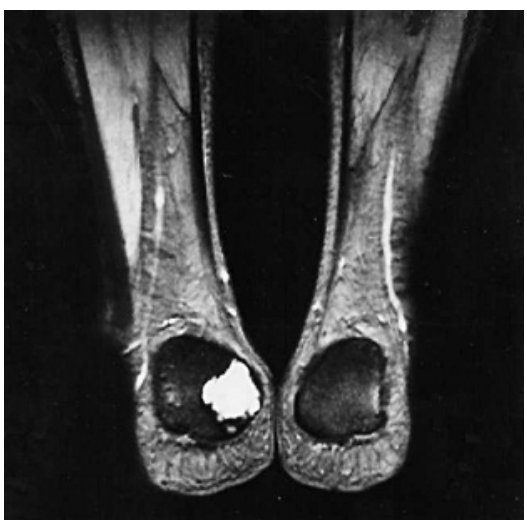

Figure 4 MRI scan: T2W coronal.

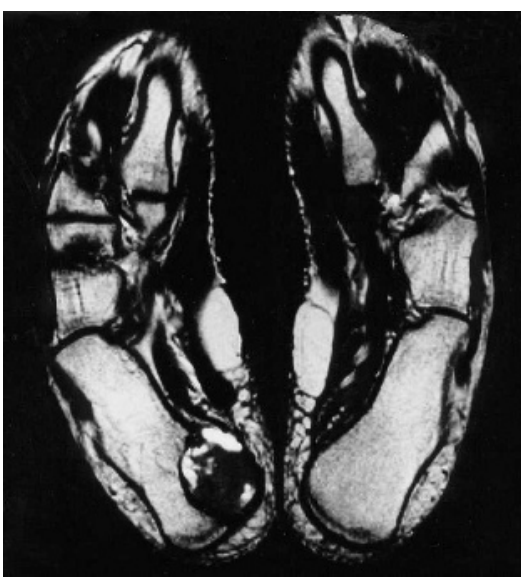

Figure $5 \mathrm{MRI}$ scan: T2W transverse plantar.

(fig 2) radiographic views of the calcaneum revealed a large lytic lesion, with generous calcifying margins, occupying the posteroinferomedial portion of the calcaneum.

Magnetic resonance imaging (MRI) showed heterogenous low signal intensity in the posterior part of calcaneum measuring $2.5 \times 2.5 \times 2.5 \mathrm{~cm}$, with a small breach in the cortex. The lesion was sharply demarcated from rest of the bone. There was no local marrow signal change and no soft tissue extension (figs 3, 4, and 5).

\section{QUESTIONS}

(1) What is the differential diagnosis?

(2) How would you proceed to confirm your diagnosis?

(3) How long would you follow up this patient?

Postgrad Med J 2004;80:241.

doi: 10.1136/pgmi.2002.002279q

\section{Authors' affiliations}

H Sharma, Department of Trauma and

Orthopaedics, Monklands Hospital, Airdrie, Lanarkshire, UK

G R Taylor, Department of Trauma and

Orthopaedics, Southampton General Hospital,

Southampton, UK

Correspondence to: Mr Sharma; himanshusharma1@hotmail.com

Submitted 12 October 2002 Accepted 18 May 2003 